\title{
La silente vida de Vicki Cassman
}

\author{
Calogero M. Santoro ${ }^{1}$
}

La reciente partida de Vicki Cassman de este mundo no sorprendió, pero profundizó la impotente pena y el dolor que se arrastraba desde hacía tiempo, a medida que su vida se apagaba. Ella trazó y marcó una huella que se fue haciendo más pronunciada e influyente, sin que significara que pidiera o se hiciera acompañar de la sonajera de bandas de bronces, de challa y serpentina, elementos típicos de carnavales y ceremonias que hoy día, figurativamente, forman parte de las prácticas promocionales en muchos ámbitos del quehacer humano; derivadas de la incontenible necesidad de ser visualizados minuto a minuto en la aldea global (Jin y Ryu 2018:555). Este comportamiento del siglo XXI, no tocó las nervaduras del sistema de vida de Vicki, tanto en el campo académico como familiar. Por el contrario, ella le dio otro sentido a su humanidad, lo que me recuerda el momento de una dulce foto de Vicki con su hijo Víctor Alejandro en el paisaje desértico de la Quebrada de Chaca (que acompaña este texto), y al mismo tiempo rememoro la pesadumbre que le suscitaba la adoración que causaba su hijo, en nuestro medio multiétnico, dado que quería evitar que se incubaran en él mecanismos de comportamiento como los señalados por Jin y Ryu (2018).

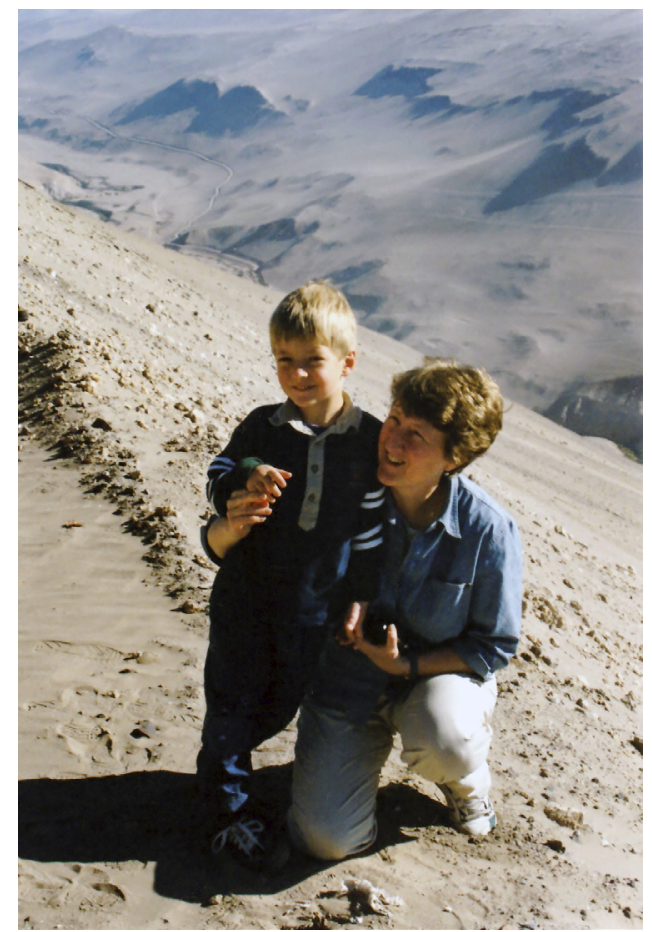

Vicki y Victor Alejandro en el borde de la profunda y árida ladera de la Quebrada de Chaca, invierno 1999.
Pero al margen de la posición de Vicki frente a la vida y su existencia en la tierra, su aporte a la historia de la arqueología andina y del norte de Chile en general es fundamental, por lo que debería agregarse y reconocerse en lalargaguirnaldadefulgurantespersonajesmasculinos, como Max Uhle, Junius Bird, Richard Schaedel, Virgilio Schiappacasse, Hans Niemeyer, John Murra y muchos otros más que han sido homenajeados en las páginas de Chungara y en otros medios de difusión científica nacionales e internacionales; lo que contrasta con el corto número de mujeres investigadoras reconocidas, entre las que destacan, Grete Mostny, Bente Bittmann, Olivia Harris y ahora Vicki Cassman.

Vicki abrió en Arica, con fundamentos científicos, la discusión en el campo de la museología, con especial énfasis en la parte oculta o no pública de los museos, como son el manejo de colecciones, con sus sistemas de inventario, catalogación, conservación y administración de la diversidad de objetos que forman parte del capital museológico del país, cuyo resguardo debe asegurarse para generaciones presentes y futuras de visitantes y estudiosos del contenido físico e inmaterial encapsulados en los Museos. La discusión, sin embargo, Vicki la condujo siempre en un ambiente de relaciones horizontales con todos los estamentos del Museo San Miguel de Azapa; haciendo ver que este es en sí mismo un laboratorio ideal y desafiante para desarrollar propuestas teóricas, metodológicas y prácticas de vanguardia para la museología. Dicho de otro modo, aunque contaba con el sustento intelectual de su formación en el programa de master en Art Conservation impartido en forma conjunta por el Winterthur Museum, Garden \& Library y la University of Delaware, USA, Vicki mantuvo siempre un ambiente más bien familiar de discusión, estimulante, pero respetuosa a la hora de reflexionar sobre ciertas prácticas museográficas del Museo Arqueológico San Miguel de Azapa y que de alguna manera todavía siguen vigentes (Córdova-González 2019). En este contexto, publicó un estudio en el que propuso generar una "simbiosis entre arqueología, conservación y museos", lo que sintetizó señalando la necesidad de "lograr un balance entre representación de la realidad prehistórica, la protección de la pieza arqueológica y la estética para el observador" (Cassman 1989:100). Su vocación por comprender mejor los materiales arqueológicos curados en los museos, lallevó a complementar su formación museológica con estudios de postgrado en arqueología. Así silenciosamente, hizo su tesis doctoral sobre materiales de contextos funerarios, para darles un sentido más social a los objetos conservados

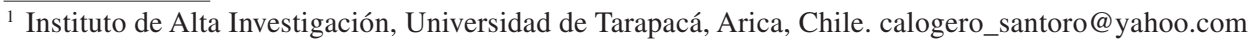


en el museo. Consecuentemente, avanzó en el problema de la identidad de los grupos sociales de los valles de Arica a través del análisis de materiales de varios cementerios del valle de Azapa, con especial referencia al periodo Medio (Cassman 2000).

Su mejor y silencioso legado, sin embargo, fue su espíritu de colaboración y de integración, expresado en detalles mínimos. Hace casi 40 años en un viaje de exploración al altiplano de Arica, muy temprano en una mañana fría y con poco oxígeno, preparábamos el desayuno que en esa época era cargado a las proteínas animales procesadas en embutidos, mezclados con huevos y vegetales enlatados. Vicki se ofreció a ayudarnos a armar este cocimiento, que ese día incluía salchichas individualmente protegidas con envolturas de plástico, un rasgo cultural desconocido en su background norteamericano y sueco por parte de sus padres; por lo que las rodajas de salchicha fueron a parar a la olla con dichos envoltorios, lo que generó desconcierto en los comensales y provocó una profunda e hilarante discusión acerca de las costumbres nacionales a base de señas, dado el corto entendimiento mutuo de inglés y español. No sé si a partir de ese momento decidió tomar el rumbo de la comida más sana, que trató de traspasar a los estudiantes y residentes de la ciudad de
Las Vegas, en el Estado de Nevada (USA), donde varios años más tarde el destino nos volvió a reunir. Allí pude constatar su espíritu conservacionista transversal y universal, materializado en una especie de performance museográfico de máquinas expendedoras de productos alimenticios sanos y balanceados derivados de cereales, frutos y semillas para la salubridad de las personas y el planeta. Su mayor legado humano, a mi juicio, fue el resultado de una integración profunda con Sudamérica a través de su unión intelectual y familiar con Bernardo Arriaza (huaso oriundo de Coltauco en la zona central de Chile, afincado en Arica) y su descendencia en Víctor Alejandro Arriaza Cassman quien, posiblemente, reproducirá este encuentro en nuevas generaciones. Esta integración de alguna manera fue profetizada por su padre, al comienzo de los tiempos, cuando estando Vicki a punto de tomar el avión en el aeropuerto de Los Angeles para venir por primera vez a Chile, le dijo algo así como: "espero que te vaya muy bien, pero por favor no traigas de vuelta a un chileno". Si no lo hubiera mencionado, no estaríamos escribiendo esta nostálgica crónica. Adiós querida Vicki, tu recuerdo seguirá girando entre nosotros, como los torteros de las tejedoras andinas de los valles de Arica, cuyo estudio no quedará "inconcluso" como la Sinfonía 8 de Franz Schubert.

\section{Referencias Citadas}

Cassman, V. 1989. Simbiosis entre la arqueología, conservación y museos. Chungara Revista de Antropología Chilena 23:93109.

Cassman, V. 2000. Prehistoric ethnicity and status based on textile evidence from Arica, Chile. Chungara Revista de Antropología Chilena 32:253-257.
Córdova-González, J. 2019. Interpretaciones del Pasado Remoto en un Museo de Arqueología. Santiago.

Jin, S. V. y E. Ryu 2018. "The paradox of Narcissus and Echo in the instagram pond" in light of the selfie culture from Freudian evolutionary psychology: self-loving and confident but lonely. Journal of Broadcasting \& Electronic Media 62:554-577. 